\title{
Gallic acid enhances the antitumor activity of Icotinib hydrochloride in non-small cell lung cancer via of Hippo- YAP signaling pathway in vitro and in vivo
}

\section{Yinghua Guo \\ Chinese PLA General Hospital \\ Yuan Liu \\ Chinese PLA General Hospital}

Dapeng Wang ( $\sim$ wangdapeng1031@163.com )

Chinese PLA General Hospital https://orcid.org/0000-0001-6193-098X

\section{Rengerile Sa}

Inner Mongolia Medical University

Junfeng Wang

Chinese PLA General Hospital

\section{Bin Zhang}

Binzhou Medical College: Binzhou Medical University

\section{Po Bai}

Chinese PLA General Hospital

\section{Xiaolei Su}

Chinese PLA General Hospital

\section{Xuelin Zhang}

Chinese PLA General Hospital

\section{Yongqing Zhang}

Chinese PLA General Hospital

Changting Liu

Chinese PLA General Hospital

\section{Research Article}

Keywords: Gallic acid, Icotinib hydrochloride, NSCLC, Combination therapy, YAP

Posted Date: January 28th, 2022

DOI: https://doi.org/10.21203/rs.3.rs-1217354/v1

License: (c) (1) This work is licensed under a Creative Commons Attribution 4.0 International License. Read Full License 


\section{Abstract}

Icotinib hydrochloride $(\mathrm{IH})$ is a small molecular TKI independently developed in China. As the first-line anti-tumor agent, is widely used for treatment of non-small cell lung cancer (NSCLC). Gallic acid (GA), a natural plant extract, is reported that it has a variety of pharmacological and biological properties. GA is a active natural phenolic extracted from Tannins that has been shown to exhibit anticancer activities on various types of tumors. Here, we reported that GA was capable of sensitizing A549/PC9 cells to IH by enhancing apoptosis. Mechanistic analyses indicated that $\mathrm{IH}$-induced caspase-3-dependent apoptosis was elevated in the presence of GA through activating extracellular signal-regulated Hippo-YAP pathway. Furthermore, GA also promoted IH-induced cytotoxic, downregulated expression of p-YAP and caspase-3. In vivo, the co-treatment of $\mathrm{IH}$ and GA notably reduced the tumor size when compared with $\mathrm{IH}$ treatment alone. Notably, GA significantly reduced the toxicity generated by $\mathrm{IH}$ in tumor-bearing mice. This study identifies the unique role of GA enhance IH sensitivity through apoptosis, and suggests that combined IH and GA might be a novel therapeutic strategy for patients with NSCLC.

\section{Introduction}

As one of the most usual malignant tumors, lung cancer has been the malignant tumor with the greatest morbidity and mortality across the world since the 1990s [1]. Though the techniques of surgery and chemotherapy have been improved, the 5 -year survival rate of patients is below $20 \%$ due to the limitations of surgical treatment and the side effects of chemotherapy drugs [2]. Tyrosine kinase inhibitors (TKIs) of epidermal growth factor receptor (EGFR), as the main driver gene in NSCLC has become one of research hotspots. The anticancer efficacies of current therapies are limited, due to the high degree of cancer clonal heterogeneity. In addition, using a single therapeutic agent is not effective in eradicating cancer cells, and hence the use of combinatorial therapy, which could inhibit multiple targets or redundant pathways simultaneously, is essential and inevitable. Scholars have evaluated a lot of methods such as integration of EGFR-TKIs with natural plant extract for progression delaying.

Gallic acid (GA, Figure1) is rich in grapes, tea, nuts and red wine as a plant extract and natural phenolic compound [3]. According to report, it shows various pharmacological and biological nature such as antibacterial activity [4], antiviral activity [5] and antioxidants [6]. The anti-tumor function of GA has been brought into focus recently. According to researches, GA may stop the development of malignant tumors by stopping the propagation and aggressive activity of tumors [7-11]. Also, GA exerts an excellent inhibitory effect on the tumors such as cervical cancer [12], breast cancer [11], lung cancer [13] and prostate cancer [14]. Thus, it was expected that GA integrated with TKIs may play a better prohibitive role in NSCLC.

Icotinib hydrochloride (IH, Figure1) belongs to highly efficient and specific EGFR-TKIs and was independently developed in China. Clinically, IH has been extensively applied in China with similar clinical potency and greater security compared with gefitinib [15-16]. The Hippo-YAP signaling pathway is able to adjust the organ size and maintain the dynamic balance between cell propagation and apoptosis as a significant signaling pathway and a tumor suppressor. Many studied have illustrated that the Hippo-YAP signaling pathway can participate in the development of tumor by affecting cell proliferation and apoptosis. YAP and caspase-3 are two important genes in Hippo-signaling pathway. However, whether YAP and caspase-3 are involved in GA-IH interaction has not been reported. This research aimed at evaluating the antitumor role of GA integrated with $\mathrm{IH}$, to explore the mechanisms underlying synergistic interactions between $\mathrm{GA}$ and $\mathrm{IH}$, and provided a new therapeutic target for increased $\mathrm{IH}$ sensitivity. 


\section{Methods And Materials \\ 2.1 Materials and reagents}

The human NSCLC A549 and PC9 cell lines were obtained from the Hunan Fenghui Biotechnology Co., Ltd (Hunan China), RPMI 1640 and fetal bovine serum were from Thermo Fisher Scientific and penicillin/streptomycin was from Solarbio (Beijing, China) GA with purity above $98 \%$ was purchased from Sigma-Aldrich Chemical Co. (St. Louis, MO, USA). IH was kindly provided by Zhejiang Beta Pharma Co., Ltd. (Zhejiang, China). Fetal bovine serum (FBS) and RPMI-1640 medium were purchased from Gibco-BRL (Grand Island, NY, USA). The cell apoptosis detection kit with Annexin V-fluorescein Isothiocyanate (FITC)/Propidiumiodide (PI), was purchased from Beyotime Institute of Biotechnology (Jiangsu, China). Primary antibodies against Yap, p-Yap, Cappase-3, and $\beta$-actin were purchased from SantaCruz Biotechnology, Inc. (Santa Cruz, CA, USA).

\subsection{Patients}

6 cases of primary lung cancer and 6 cases of paracancers from June 2019 to September 2019 were collected from the Department of Pathology, Chinese PLA General Hospital. There were 4 males and 2 females, who aged from 42 to 68 years old, with an average age of $(59.24 \pm 5.76)$ years. Histological type was adenocarcinoma; All selected patients underwent radical resection without chemotherapy or radiotherapy before operation. The study was approved by the hospital ethics committee.

\subsection{Cell Culture}

Human NSCLC A549 and PC9 cell lines were cultured in RPMI-1640 medium containing 10\% FBS at $37^{\circ} \mathrm{Cin}$ a humidified $5 \% \mathrm{CO}_{2}$ incubator. The medium was changed 2 3 times every week and the cells were used in their logarithmic growth phase.

\subsection{Human lung tissue immunohistochemistry}

Tissue specimens were fixed in $10 \%$ neutral formalin solution for $48 \mathrm{~h}$, embedded in conventional paraffin. 3 raffin in convent were baked in $60^{\circ} \mathrm{C}$ oven for $30 \mathrm{~min}$, followed by dewaxing, antigen retrieval, antigen exposure, sealing and dripping peroxide. The operation steps were carried out according to the operating instructions of the Roche automatic immunohistochemistry instrument. The primary antibody dripped manually, and finally, it was counterstained with artificial hematoxylin, blue back, and sealed with a neutral gum sheet. The primary antibody of immunohistochemistry was rabbit anti-human caspase-3, YAP, p-YAP polyclonal antibody (1:200, Santa Cruz, USA). Immunohistochemical staining scoring was judged by the intensity of nuclear staining or cytoplasm staining in tumor tissues and paracancers. The widely accepted German semi-quantitative scoring system was used to score staining intensity and extent in different areas. Each specimen was assigned a score according to the intensity of the nuclei, cytoplasmic, and membrane staining (no staining $1 / 40$; weak staining $1 / 41$, moderatestaining $1 / 42$, and strong staining $1 / 43)$ and the extent of stained cells $\left(0-5 \% 1 / 40,5-25 \% 1 / 41,26-50 \% \frac{1}{4} 2,51-75 \% 1 / 43\right.$ and $\left.76-100 \% 1 / 44\right)$. The final immunoreactivity score was determined by multiplying the intensity score by the score for the extent of stained cells, generating a score that ranged from 0 (the minimumscore) to 12 (the maximum score). 


\subsection{Cell viability assay}

According to the manufacturer's instructions, cell viability was evaluated using MTT (Solarbio, Beijing,China). Briefly, cells were seeded into 96-well plates at $8 \times 10^{3}$ cells per well and cultured for 48 hours (control group, GA group, IH Group, GA+IH group). Ten microlitres of MTT (concentration: $5 \mathrm{mg} / \mathrm{ml}$ ) solution was added into the medium in each well. After a $4 \mathrm{hr}$ incubation, the supernatants were removed from each well, and 100 $\mu$ DMSO was added to each well. The plate was incubated with shaking at room temperature for 15 minutes and red by a microplate reader (BioTek Company,Winooski, VT) at a wavelength of 570nm. Each timepoint was repeated in three wells, and the experiment was independently performed three times.

\subsection{Drug combination research}

To evaluate the combined index $(\mathrm{Cl})$ of the effect of GA with IH on the growth of A549 and PC9 cells, the inhibitory effect of varying concentration of IH combined with varying concentrations of GA on the growth of A549 and PC9 cells was analyzed. CalcuSyn software (version2.0) was used to calculate the $\mathrm{Cl}$ of $\mathrm{GA}$ combined with $\mathrm{IH}$. $\mathrm{Cl}>1.1$ : antagonism; $0.9 \otimes \mathrm{Cl} \otimes 1.1$ : anadditive effect; $0.7<\mathrm{Cl}<0.9$ : low synergy; $0.3 \otimes \mathrm{Cl} \otimes 0.7$ : synergy; $0.1 \otimes \mathrm{Cl} \otimes 0.3$ : strong synergy.

\subsection{Cell apoptosis assay}

Cell apoptosis was evaluated by flow cytometry using an Annexin V-FITC Apoptosis Detection Kit (KeyGen Biotech, Nanjing, China). Briefly, cells were seeded into 24 -wellplates at $5 \times 10^{5}$ cells per well and cultured for $48 \mathrm{hr}$ (control group, GA group, IH Group, GA+IH group). Then the cells were detached by trypsinization, washed twice in PBS (2000 r.p.m., $5 \mathrm{~min}$ ), and resuspended in $500 \mu \mathrm{l}$ binding buffer. A volume of $5 \mu$ I Annexin V-FITC and $10 \mu l$ propidium iodide was added and mixed gently, and the cells were stained in the dark for $10 \mathrm{~min}$ at room temperature. The cells were analyzed immediately by flow cytometry (BD FACSCalibur, BD. Bioscience, San Diego, CA) and analyzed using FLOWJO software (FlowJo, Ashland, OR). The experiment was repeated three times.

\subsection{Transwell migration assay}

The ability of cell migration was measured by Transwell assay. The cells density was adjusted to $5 \times 10^{5}$ cells $/ \mathrm{ml}$. In addition, $200 \mu \mathrm{L}$ cell suspension was put into the upper chamber of Transwell cells, and then $600 \mu \mathrm{L}$ complete medium (control group, GA group, IH Group, GA+IH group) was added to the lower chamber of 24-well culture plate. The culture plate was placed in a $\mathrm{CO}_{2}$ incubator at $37^{\circ} \mathrm{C}$ for $48 \mathrm{hr}$. It was took out the Transwell, and washed twice with PBS. In addition, the matrix glue and the cells in the chamber were wiped off with a cotton swab. Moreover, it was soaked in $70 \%$ methanol for $30 \mathrm{~min}$, and dyed with crystal violet. After crystal violet staining, the stained migrating cells can be decolorized with $33 \%$ acetic acid, crystal violet can be completely eluted, and then the OD value of the eluent at $570 \mathrm{~nm}$ was determined by microplate reader, which indirectly reflected the number of migrating cells. The experiment was repeated at least three times.

\subsection{Real-time qPCR (qPCR)}


A549 and PC9 cells, passaged in a 6-well plate at $2 \times 10^{5} / \mathrm{L}$, were cultured in an incubator for $24 \mathrm{hr}$, and different intervention drugs were added (control group, GA group, IH Group, GA+IH group). After $48 \mathrm{hr}$ of treatment, cells were collected, total RNA was extracted with RNA Isolation Kit (SinoGene, Beijing, Chaina) and reverse transcribed using The First Strand Synthsis Kit (SinoGene, Beijing, China). The qPCR was performed using SYBR MasterMix Kit (SinoGene, Beijing, China). ACTB was used as an internal reference gene to detect the expression of Caspase-3 and YAP (Primers in the Table 1).The2 $\triangle \triangle \mathrm{Ct}$ method was used to caclulate the relative mRNA expression.

\subsection{Western blot}

Cells were treated with $\mathrm{GA}, \mathrm{IH}$, and $\mathrm{GA}+\mathrm{IH}$ for 48 hours and then harvested and lysed in RIPA buffer (SinoGene, China) containing $1 \%$ phosphatase for total protein extraction. $30 \mu \mathrm{g}$ proteins per samples were separated via SDSPAGE and transferred to PVDF membranes after quantification by the Pierce BCA protein assay Kit (Thermo Fsiher Sceinetifc, USA) and boiled for 10 minutes with protein loading buffer. Protein Marker (SM26616, Thermo Fermentas, USA) was loaded at the first lane. the membranes were incubated with different primary antibodies anticaspase-3, YAP, p-YAP (1:1000) at room temperature for 1 hour and then exposed to HRP-conjugated secondary antibody (1:3000) for $1 \mathrm{hr}$. Finally, membranes were exposed to films with ECL luminescent solution (29050, Engreen, China) in the darkroom. Beta-actin (1:3000, AC028, Abclonal, China) was as loading control.

\subsection{Animal study}

A total of 24 BALB/C nude mice (4 weeks old, 18-22 g) were purchased from the Experimental Animal Center. The study was approved by the Research Ethics Committee oftheChinease PLA General Hospital. Under sterile conditions, $0.2 \mathrm{ml}$ (PC9) of cell suspension ( $\mid \times 10^{7}$ cells $/ \mathrm{mL}$ ) was pipetted with a $1 \mathrm{~mL}$ disposable syringe and slowly injected into the right armpit of the nude mice. The long diameter of the tumor block $>1 \mathrm{~mm}$ and felted lumps was indicative of the successful establishment of the NSCLC mouse model. After successful modeling, animals were divied into 4 groups: control group, GA group (30 $\mathrm{gg} / \mathrm{kg})$, IH group $(100 \mathrm{mg} / \mathrm{kg})$, and combined treatment group $(30 \mu \mathrm{g} / \mathrm{kg}+100 \mathrm{mg} / \mathrm{kg})$ and thenadministration for $14 \mathrm{~d}(1 \mathrm{time} / \mathrm{d})$. During the administration, the long diameter and short diameter of the transplanted tumors were measured by vernier calipers every $3 d$, repeated in triplicate to obtain the average values. The tumor volume was then calculated: $V=$ long diameter $\times$ short diameter ${ }^{2} / 2$, and the growth curve of the transplanted tumors were plotted based on the values obtained. Each mouse was heparinized by intraperitoneal injection of $0.5 \%$ heparin $(0.5 \mathrm{~mL})$, and then eye blood were collected to measure the levels of alanine aminotransferase (ALT) and alkaline phosphatase (ALP), blood urea nitrogen (BUN) and creatinine (Cr) after the last administration on the 14th day. In addition, the animals were euthanized with carbon dioxide asphyxiation, the tumors were removed, and the volumes of the tumors were measured after weighing the animals. In addition, protein expressions of caspase-3, YAP and $p$-YAP in tumors was detected by immunohistochemical staining, and the percentage of caspase-3, YAP and p-YAP protein positive staining was quantified. A microscope (IX510lympus, Japan) and Image Pro Plus software were used to take photos and analyze slides.

\subsection{Statistical analysis}

The quantitative experiments were performed in triplicates, and the data were represented as the mean \pm standard deviation (S.D.). A statistical comparison of the data was conducted using One-way ANOVA followed by Tukey's 
honest significant difference (HSD) test in post-hoc comparisons. Statistical significance between two groups was defined as $\mathrm{P}<0.05$.

\section{Results}

\subsection{Immunohistochemical staining of human NSCLC and paired paracancers}

First of all, the expression of caspase-3, YAP and p-YAP in 6 NSCLC specimens were analyzed by IHC. The results showed caspase-3 was high expressed in normal lung tissues, but weakly expressed in NSCLC tissues. Compared with normal lung tissues, more YAP expression was detected in NSCLC tissues; Otherwise, the phosphorylation of YAP was downregulated in NSCLC tissues. In immunohistochemical staining, the positive granules were yellow or brown. All of them were located in the nucleus, and were granular, dispersed and/or mixed (Figure 2; Table2).

\subsection{Inhibitory effect of GA/IH on A549/PC9 cells}

A549/PC9 cells were inoculated into 96 well plates with $4 \times 10^{3}$ cells per well and treated with different concentrations of GA $(0,33,66,132,264,528 \mu \mathrm{M}) / \mathrm{IH}(0,0.1,0.5,1.0,5.0,10 \mu \mathrm{M})$. After $48 \mathrm{~h}$ treatment, the growth of A549/PC9 cell lines treated with different concentration of GA/IH was detected by MTT assay. The cell survival rate decreased significantly $(p=0.000)$ after treated with 264 and $528 \mu \mathrm{M} \mathrm{GA}(p=0.000)$. However, 66 and $132 \mu \mathrm{M}$ did not

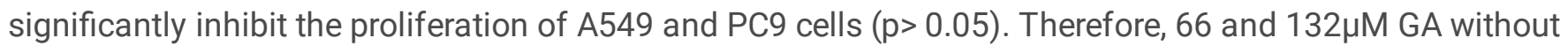
cytotoxicity were used for further study to effectively evaluate the sensitization of GA to IH (Figure 3A; Table3A). Both A549 and PC9 cells were inhibited by IH, but the sensitivity of both cells to IH was different. The results further confirmed that the effect of IH on mutant EGFR cell line (PC9) was stronger than that of wild-type EGFR cell line (A549). A549/PC9 were treated with $10 \mu \mathrm{M} / 1.0,5.0$ and $10 \mu \mathrm{M} \mathrm{IH}$ compared with the control group, the cell survival rate decreased significantly $(\mathrm{p}=0.000)$. However, $0.1,0.5,1.0,5.0 \mu \mathrm{M} / 0.1,0.5 \mu \mathrm{M}$ did not significantly inhibit the proliferation of A549/PC9 cells ( $p>0.05$ ) (Figure3B; Table 3B). Therefore, we used non-cytotoxic 0.5, 1.0, 5.0 $\mu \mathrm{M} \mathrm{IH} \mathrm{in}$ combination with 66 and $132 \mu \mathrm{M}$ GA to evaluate the sensitization of GA to $\mathrm{IH}$.

\subsection{GA enhanced the drug susceptibility of IH in A549/PC9 Cells}

A549/PC9 cells were inoculated into 96 well plates with $4 \times 10^{3}$ cells per well, the cells were treated with $\mathrm{IH}(0.5,1.0$, $5.0 \mu \mathrm{M})$ in combination with $\mathrm{GA}(66$ and $132 \mu \mathrm{M})$, and the cell survival rate was measured by MTT Assay. The synergistic antitumor effect of IH and GA was evaluated using COMPUSYN software. The Synergy Index (Cl) was used to evaluate the synergy between $\mathrm{GA}$ and $\mathrm{IH}$. Combinated $0.5,1.0,5.0 \mu \mathrm{M} \mathrm{IH}$ and $66,132 \mu \mathrm{M} \mathrm{GA}$ showed a abvious synergism (Figure 3C-D). Thus, IH and GA yield a synergistic effect in killing A549/PC9 cells. Specifically, 132 $\mu M$ GA was stronger than that treated with $66 \mu \mathrm{M} \mathrm{GA}, 132 \mu \mathrm{M}$ GA did not yield measurable impacton cell viability of A549/PC9 cells, but clearly enhanced the sensitivity of A549/PC9 to IH. Also, as shown in Figure 3C, the efficiency of $5 \mu \mathrm{M}$ (A549) or $0.5 \mu \mathrm{M}$ (PC9) IH combined with $132 \mu \mathrm{M}$ GA peaked at 48h. Here $132 \mu \mathrm{M}$ GA and $5 \mu \mathrm{M}(\mathrm{A} 549)$ or $0.5 \mu \mathrm{M}$ (PC9) IH have synergistic index of 0.65 and 0.67(Table 6). Thus, IH And GA yielda synergistic effect in killing A549/PC9 cells. So $132 \mu \mathrm{M}$ GA and $5 \mu \mathrm{M}$ (A549) or $0.5 \mu \mathrm{M}$ (PC9) IH were used for further study.

\subsection{GA Increased IH-induced apoptosis}


We examined whether GA could enhance IH-induced apoptosis using flow cytometry in A549/PC9 cells. Apoptosis plays a key role in governing anticancer therapy, yet its involved mechanisms are largely unknown. As observed, the number of apoptosis were elevated in A549/PC9 cells exposed to co-treatment of $\mathrm{IH}$ and GA, compared with $\mathrm{IH}$ alone, or GA alone (Figure 4), indicating GA indeed enhanced IH-induced apoptosis. The results showed that the apoptosis rate in the combination group (30.93\%/33.54\%) was significantly higher than that in the GA (17.59\%/17.55\%) and IH (27.31\%/32.32\%) groups in the A549/PC9 cell groups (Figure $4, * P<0.05 \rrbracket * * P<0.01 \square$ $\star \star \star P<0.001)$. Together, these findings suggested that GA may promote $\mathrm{IH}$ - induced apoptosis, of which was not cytoprotective, but lead to cell death.

\subsection{GA enhances IH suppressed migration}

It was detected by Transwell test in order to study the effect of GA, IH and combination therapy on the migration of A549 and PC9 cells. The absorbance of acetic acid solution was read by microplate reader (570nm). The results showed significant inhibitory effects on the migration of A549 and PC9 cells were in the three treatment groups. Furthermore, the inhibition of migration of lung cancer cells was more obvious in the combination groups compared with the single drug group (Figure 5).

\subsection{GA enhances IH on mRNA expression of the key gene}

The mRNA expression of Caspase-3 and YAP in A549 and PC9 cells were analyzed by qPCR. As a result, compared with the control group, the mRNA expressions of Caspase-3 were increased and YAP were downregulated in both the single drug group and the combination group, especially in the combination group (Figure 6).

\subsection{GA Enhanced IH-Induced caspase-3-dependent apoptosis through suppressing}

\section{Hippo-YAP signaling pathway}

Similarly, we determine whether Hippo-YAP pathway participated in GA and IH-induced apoptosis. Caspase-3 is activated during apoptosis. Given that caspase-3 plays a distinct role in IH-mediated apoptosis in cancer cells (Li et al., 2015). Combination of IH and GA significantly increased caspase-3 when compared with IH alone. we examined caspase-3 expression by western blots. In the presence of GA, the IH-induced expression of caspase-3 was markedly enhanced (Figure 7A). Western blot analysis that the high expression of caspase-3 induced by the combination treatment in A549/PC9 cells (Figure 7). The expression level of YAP in the treatment group was significantly lower than that in the control group (Figure 7). This suggested that DNA repair may be blocked and induce apoptosis. These results suggested that p-YAP may be involved in regulating the anti-tumor effect of GA on A549 and PC9; GA may promote apoptosis through suppression the expression of YAP and enhance the anti-tumor effect of IH. Thus, GA enhanced IH-induced caspase-3-dependent apoptosis through suppressed the Hippo-YAP signaling pathway.

\subsection{GA enhanced antitumor efficacy of IH in vivo}


To verify our previous conclusions, we established xenograft mouse model. The PC9 cells were subcutaneously implanted into BALB/c nude mice, and the mice were treated with $\mathrm{IH}$ with or without GA. As we have shown IH significantly inhibited tumor growth, and this efficiency was significantly enhanced by GA treatment (Figure 8a-b; Table7). Furthermore, due to the toxicity of $\mathrm{IH}$, the on liver and kidney function of mice treated by $\mathrm{IH}$ was increased. However, in the presence of GA, the reaction was recovered (Table 7). Moreover, the combination of IH with GA increased the expression of caspase-3, P-YAP and reduced compared with IH alone (Figure 8c). Collectively, GA could notably improve anti-tumor effect of $\mathrm{IH}$, and reduce the toxicity generated by $\mathrm{IH}$ in vivo.

\section{Discussion}

$\mathrm{IH}$, one of the most commonly targeted Drugs, has been widely used to treat NSCLC [17]. However, its tumoricidal efficacy is often limited. Multiple mechanisms contributed to IH sensitivity have been documented, such as decreased drug absorption and inactivated apoptosis programs [18]. Unfortunately, there remains a lack of targeted treatment strategies focusing on enhance IH sensitivity. To evade this difficulty, we focused on looking for novel drugs to $\mathrm{IH}$ sensitivity. Our results offer the evidence that GA improved the sensitivity of A549/PC9 to IH. In addition, our study shows that GA may potentiate antitumor activity of IH in NSCLC line A549/PC9, suggesting the synergism of GA and IH was applied to NSCLC cells

As everyone knows, two hallmarks of cancer are proliferation sustaining and apoptosis inhibiting [19]. Proliferation can be sustained by cancer cells through the production of development elements themselves or stimulation of normal cells to offer different development elements [20-21]. Apoptosis is the predominant manner of IH-induced cell death. However, tumor cells may develop its own specific strategies to evade apoptosis, which facilitates their survival and promote resistance to anticancer therapies. Caspase-3 is a apoptotic effector that has been well studied to be involved in IH-induced apoptosis. In this study, IH markedly induced caspase- 3-dependent apoptosis, of note, its efficiency was enhanced by GA.

Hippo exerts a great role in tumor development and progression [22-23]. YAP is a core signaling pathway participating in Hippo [24-25], involved in Hippo pathway that is hyperactivated in a high many types of tumors, which drives cancer growth, inhibits apoptosis, promotes invasion and angiogenesis [26]. IH restrain Hippo activation is an key regulator of the YAP response to apoptosis caused by $\mathrm{IH}$. Our data show that GA serves an antiangiogenesis inducer that potentiated IH-induced p-YAP activation,suppressed YAP expression. Thus, cotreatment of IH and GA induced caspase-3-mediated apoptosis via suppressing Hippo-YAP pathway.

It is well established that Hippo-YAP pathway is emerging as important player in various types of cancers [27]. For example, in prostate cancer, inhibition of the Hippo-YAP pathway is sufficient to activate apoptosis [28]. Indeed, cotreatment of IH and GA significantly increased the level of phosphorylated YAP in A549/PC9 cells. The YAP oncogene has been identified as a potential target for cancer therapy. Activation of YAP contributes to the proliferation and invasion of cancer cells, and has been also considered as a biomarker in several tumor types [29]. Of note, YAP is regarded as a downstream factor of the Hippo pathway [30]. Here, we found that IH or GA alone could suppressed YAP level, however, the efficiency of combination treatment was stronger. These findings clearly indicated that GA enhanced IH-induced apoptosis via suppressing the Hippo-YAP signaling pathway. Furthermore, our in vivo experiment indicated that GA significantly enhanced IH-suppressed tumor growth, and reduced the toxicity generated by $\mathrm{IH}$.

\section{Conclusion}


In sum, our results showed that GA enhances the antitumor activity of IH in NSCLC cells. Mechanically, GA enhanced IH-induced apoptosis via Hippo-YAP signaling pathways, suggesting that Hippo-YAP signaling was the direct target of GA (Figure 10). Notably, GA may reduce the toxicity associated with repeated administration of IH in tumorbearing mice. These findings suggest that the combination of IH treatment with GA may be effectively applied for the treatment of NSCLC. In this study, A549/PC9 cells are a relatively homogeneous cell type, it is not clear whether the combination therapy is effective to other lung cancer cells. Thus, further experiments should performed to demonstrate whether GA may enhance the sensitivity of other lung cancer cells to $\mathrm{IH}$.

\section{Declaration}

\section{Declaration of Conflicting Interests}

The author(s) declared no potential conflicts of interest with respect to the research, authorship, and/or publication of this article.

\section{Ethical statement}

The current study was performed with the approval of the Ethics Committee of the the Chinese PLA General Hospital. This work was in conformity with the principles of the Helsinki Declaration. All the participants voluntarily joined the study and have signed an informed consent form (ICF). The animal experiments were approved by the institutional review board (CWO) of the Chinese PLA General Hospital, Beijing, China (ethical number: S2019-32701).

\section{References}

1. Jemal A, Bray F, Center MM et al (2011) Global cancer statistics. CA Cancer J Clin 61(2):69-90. https://doi:10.3322/caac.20107

2. Cheng H, Perez-Soler R (2018) Leptomeningeal metastases in non-small-cell lung cancer. Lancet Onco 19(1):e43-e55. https://doi:10.1016/S1470-2045(17)30689-7

3. Wang R, Ma L, Weng D (2016) Gallic acid induces apoptosis and enhances the anticancer effects of cisplatin in human small cell lung cancer H446 cell line via the ROS-dependent mitochondrial apoptotic pathway. Oncol Rep 35(5):3075-3083. https://doi:10.3892/or.2016.4690

4. Choi HJ, Song JH, Bhatt LR et al (2010) Baek SH. Anti-human rhinovirus activity of gallic acid possessing antioxidant capacity. Phytother Res 24(9):1292-1296. https://doi:10.1002/ptr.3101

5. Varela-Rodríguez L, Sánchez-Ramírez B, Hernández-Ramírez VI et al (2020) Effect of Gallic acid and Myricetin on ovarian cancer models: a possible alternative antitumoral treatment. BMC Complement Med Ther 20(1):110. https://doi:10.1186/s12906-020-02900-z

6. Giftson JS, Jayanthi S, Nalini N (2010) Chemopreventive efficacy of gallic acid, an antioxidant and anticarcinogenic polyphenol, against 1,2-dimethyl hydrazine induced rat colon carcinogenesis. Invest New Drugs 28(3):251-259. https://doi: 10.1007/s10637-009-9241-9

7. Priyadarshi K, Shirsath K, Waghela NB, Sharma A, Kumar A, Pathak C et al (2021) Surface modified PAMAM dendrimers with gallic acid inhibit, cell proliferation, cell migration and inflammatory response to augment 
apoptotic cell death in human colon carcinoma cells.J Biomol Struct Dyn39(18):6853-6869.

https://doi:10.1080/07391102.2020.1802344.

8. Sun GL, Wang D (2020) Gallic acid from Terminalia chebula inhibited the growth of esophageal carcinoma cells by suppressing the Hippo signal pathway. Iran J Basic Med Sci 23(11):1401-1408.

https://doi:10.22038/ijbms.2020.42283.9982

9. Veluri R, Singh RP, Liu Z et al (2006) Fractionation of grape seed extract and identification of gallic acid as one of the major active constituents causing growth inhibition and apoptotic death of DU145 human prostate carcinoma cells. Carcinogenesis 27(7):1445-1453. https://. doi

10. Chua KV, Fan CS, Chen CC et al (2019) Octyl Gallate Induces Pancreatic Ductal Adenocarcinoma Cell Apoptosis and Suppresses Endothelial-Mesenchymal Transition-Promoted M2-Macrophages, HSP90a Secretion, and Tumor Growth. Cells 9(1):91. https://. doi

11. Yap KM, Sekar M, Seow LJ et al (2021) Mangifera indica (Mango): A Promising Medicinal Plant for Breast Cancer Therapy and Understanding Its Potential Mechanisms of Action. Breast Cancer (Dove Med Press) 13:471-503. https://. doi

12. Zhao B, Hu M (2013) Gallic acid reduces cell viability, proliferation, invasion and angiogenesis in human cervical cancer cells. Oncol Lett 6(6):1749-1755. https://. doi

13. You BR, Kim SZ, Kim SH et al (2011) Gallic acid-induced lung cancer cell death is accompanied by ROS increase and glutathione depletion. Mol Cell Biochem 357(1-2):295-303. https://doi: 10.1007/s11010-011-0900-8

14. Rahman MA, Hannan MA, Dash R et al (2021) Phytochemicals as a Complement to Cancer Chemotherapy: Pharmacological Modulation of the Autophagy-Apoptosis Pathway. Front Pharmacol 12:639628. https://. doi

15. Cui S, Xiong L, Lou Y, Shi H et al (2016) Factors that predict progression-free survival in Chinese lung adenocarcinoma patients treated with epidermal growth factor receptor tyrosine kinase inhibitors. $J$ Thorac Dis 8(1):68-78. https://. doi

16. Shi Y, Zhang L, Liu X et al (2013) Icotinib versus gefitinib in previously treated advanced non-small-cell lung cancer (ICOGEN): a randomised, double-blind phase 3 non-inferiority trial. Lancet Oncol 14(10):953-961. https://doi:10.1016/S1470-2045(13)70355-3

17. Liang JL, Ren XC, Lin Q (2014) Treating advanced non-small-cell lung cancer in Chinese patients: focus on icotinib. Onco Targets Ther 16:7:761-770. https://. doi

18. Chen P, Dai CH, Shi ZH et al (2021) Synergistic inhibitory effect of berberine and icotinib on non-small cell lung cancer cells via inducing autophagic cell death and apoptosis. Apoptosis 26(11-12):639-656. https://doi: 10.1007/s10495-021-01694-w

19. Caponnetto F, Dalla E, Mangoni D et al (2020) The miRNA Content of Exosomes Released from the Glioma Microenvironment Can Affect Malignant Progression. Biomedicines 8(12):564. https://. doi

20. Varahan S, Walvekar A, Sinha V et al (2019) Metabolic constraints drive self-organization of specialized cell groups. eLife 2019; e46735. doi: 10.7554/eLife.46735

21. Huang K, Li Q, Li Y et al (2018) Cartilage Tissue Regeneration: The Roles of Cells, Stimulating Factors and Scaffolds. Curr Stem Cell Res Ther 13(7):547-567. https://doi:10.2174/1574888X12666170608080722

22. Sasaki H (2017) Roles and regulations of Hippo signaling during preimplantation mouse development. Dev Growth Differ 59(1):12-20. https://doi:10.1016/j.apsb.2015.07.008

23. Boopathy GTK, Hong W (2019) Role of Hippo Pathway-YAP/TAZ Signaling in Angiogenesis. Front Cell Dev Biol 7:49. https://. doi

Page $10 / 23$ 
24. Liu M, Zhao S, Lin Q et al (2015) YAP regulates the expression of Hoxa1 and Hoxc13 in mouse and human oralandskin epithelial tissues. Mol Cell Biol 35(8):1449-1461. https://. doi

25. Yoo G, Park D, Kim Y et al (2021) New Insights into the Clinical Implications of Yes-Associated Protein in Lung Cancer: Roles in Drug Resistance, Tumor Immunity, Autophagy, and Organoid Development. Cancers (Basel) 13(12):3069. https://. doi

26. Tumosienė I, Jonuškienė I, Kantminienė K et al (2021) Novel N-Substituted Amino Acid Hydrazone-lsatin Derivatives: Synthesis, Antioxidant Activity, and Anticancer Activity in 2D and 3D Models In Vitro. Int J Mol Sci 22(15):7799. https://doi:10.3390/ijms22157799

27. Zindel D, Mensat P, Vol C et al (2021) G protein-coupled receptors can control the Hippo/YAP pathway through Gq signaling. FASEB J 35(7):e21668. https://doi:10.1096/fj.202002159R

28. Moroishi T, Park HW, Qin B et al (2015) A YAP/TAZ-induced feedback mechanism regulates Hippo pathway homeostasis. Genes Dev 29(12):1271-1284. https://doi:10.1101/gad.262816.115

29. Caponnetto F, Dalla E, Mangoni D et al (2020) The miRNA Content of Exosomes Released from the Glioma Microenvironment Can Affect Malignant Progression. Biomedicines 8(12):564. https://. doi

30. Varahan S, Walvekar A, Sinha V et al (2019) Metabolic constraints drive self-organization of specialized cell groups. eLife 2019; e46735. doi: 10.7554/eLife.46735

31. Mao X, Li P, Wang Y et al (2017) CRB3 regulates contact inhibition by activating the Hippo pathway in mammary epithelial cells. Cell Death Dis 8(1):e2546. https://. doi

32. Maehama T, Nishio M, Otani J et al (2021) The role of Hippo-YAP signaling in squamous cell carcinomas. Cancer Sci 112(1):51-60. https://. doi

33. Salem O, Hansen CG (2019) The Hippo Pathway in Prostate Cancer. Cells 8(4):370. https://. doi

34. Yang F, Li L, Zhang J et al (2020) TRIP6 accelerates the proliferation and invasion of cervical cancer by upregulating oncogenic YAP signaling. Exp Cell Res 396(1):112248. https://doi:10.1016/j.yexcr.2020.112248

35. Bian SB, Yang Y, Liang WQ et al (2021) Leukemia inhibitory factor promotes gastric cancer cell proliferation, migration, and invasion via the LIFR-Hippo-YAP pathway. Ann NY Acad Sci 1484(1):74-89. https://. doi

\section{Tables}

Table 1

Primers for the target genes used in qPCR

\begin{tabular}{|llll|}
\hline Gene Name & Size[bp] & & Primers Sequences (5' to 3') \\
ACTB & 131 & Forward & GCCAACACAGTGCTGTCTGG \\
& & Reverse & GAGTACTTGCGCTCAGGAGGAG \\
Caspase-3 & 100 & Forward & GGTTCATCCAGTCGCTTTGT \\
& & Reverse & AATTCTGTTGCCACCTTTCG \\
YAP & 91 & Forward & GCAGTTGGGAGCTGTTTCTC \\
& & Reverse & CTGTCGAAGATGCTGAGCTG \\
\hline
\end{tabular}


Table 2

Scores for key protein expressions in 6 cases of human lung adenocarcinoma

\begin{tabular}{|lll|}
\hline Proteins & \multicolumn{2}{l|}{ Scores for the protein expression levels in } \\
\cline { 2 - 3 } & lung adenocarcinoma tissues & adjacent normal lung tissues \\
\hline Caspase-3 & 0 & 1 \\
\hline YAP & 2 & 0 \\
\hline P-YAP & 1 & 3 \\
\hline
\end{tabular}

Table 3

Inhibitory effect of GA on A549/PC9 cells

\begin{tabular}{|c|c|c|}
\hline Groups & A549 Cell Viability (\%) & PC9 Cell Viability (\%) \\
\hline $\mathrm{GA}(\mu \mathrm{M})$ & $48 \mathrm{~h}$ & $48 \mathrm{~h}$ \\
\hline control & $76.52 \pm 0.51$ & $76.58 \pm 0.48$ \\
\hline 33 & $73.27 \pm 0.67$ & $73.8 \pm 0.81$ \\
\hline 66 & $70.36 \pm 1.34$ & $71.78 \pm 0.67$ \\
\hline 132 & $67.57 \pm 0.58$ & $68.52 \pm 1.12$ \\
\hline 256 & $45.84 \pm 2.22^{\star}$ & $48.98 \pm 0.91 \Delta$ \\
\hline 528 & $41.21 \pm 0.51^{*}$ & $46.42 \pm 2.98 \Delta$ \\
\hline
\end{tabular}

Table 4

Inhibitory effect of IH on A549/PC9 cells 


\begin{tabular}{|c|c|c|}
\hline Groups & A549 Cell Viability (\%) & PC9 Cell Viability (\%) \\
\hline $\mathrm{GA}(\mu \mathrm{M})$ & $48 \mathrm{~h}$ & $48 \mathrm{~h}$ \\
\hline control & $76.02 \pm 1,19$ & $76.62 \pm 0.49$ \\
\hline 0.1 & $75.51 \pm 0.82$ & $74.82 \pm 0.54$ \\
\hline 0.5 & $74.76 \pm 0.69$ & $67.88 \pm 0.91$ \\
\hline 1 & $73.84 \pm 0.37$ & $59.48 \pm 1.35 \Delta$ \\
\hline 5 & $71.39 \pm 1.15$ & $46.56 \pm 2.34 \Delta$ \\
\hline 10 & $46.32 \pm 0.84^{*}$ & $42.52 \pm 0.97 \Delta$ \\
\hline \multicolumn{3}{|c|}{${ }^{*} p \otimes 0.05$ vs control group; $\triangle p \rrbracket 0.05$ vs control group } \\
\hline
\end{tabular}

Table 5

GA enhanced the drug susceptibility of IH in A549/PC9 cells.

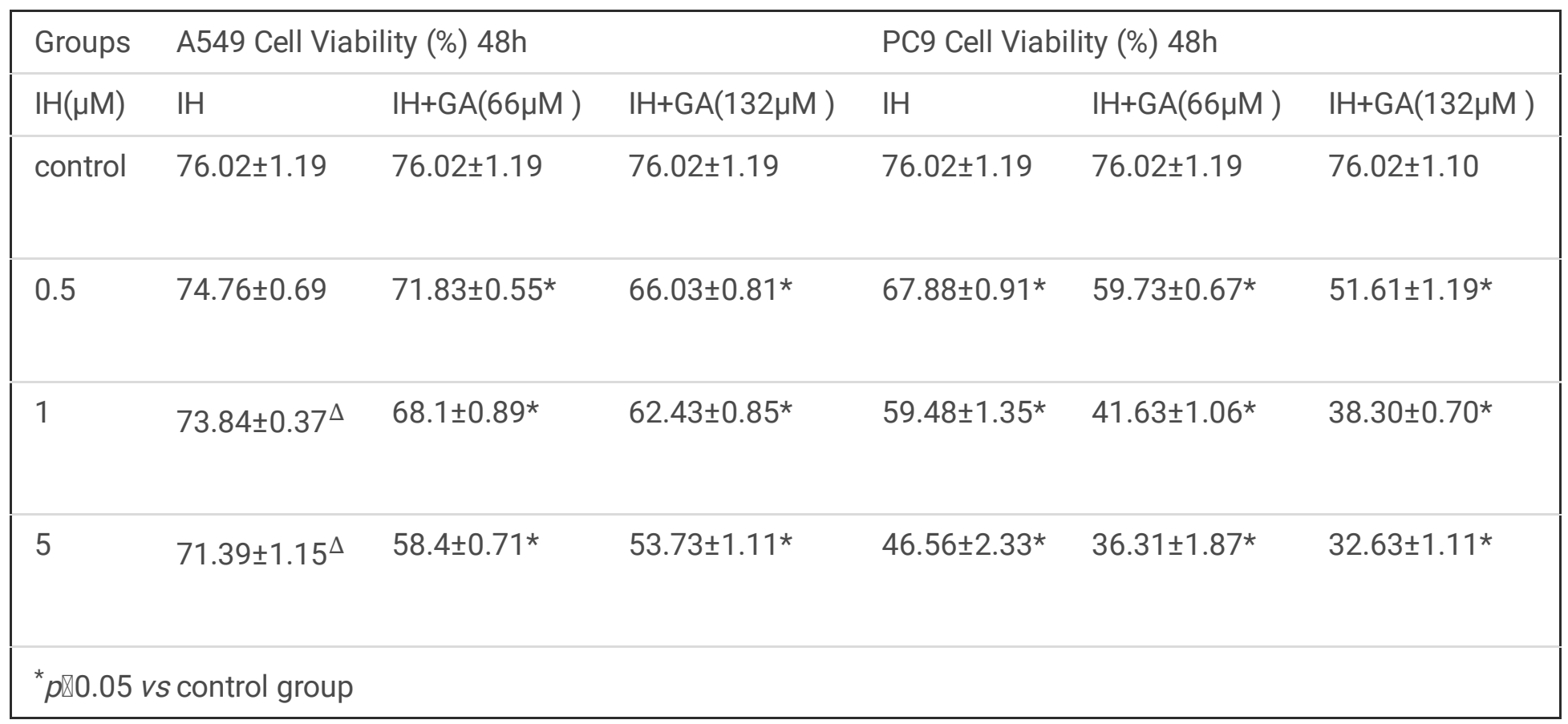

Table 6

GA enhanced the drug susceptibility of IH 


\begin{tabular}{|c|c|c|c|c|}
\hline Groups & A549 & $\mathrm{Cl}$ & PC9 & $\mathrm{Cl}$ \\
\hline $\mathrm{IH}(0.5 \mu \mathrm{M})+\mathrm{GA}(66 \mu \mathrm{M})$ & $0.748 \pm 0.013$ & 0.74 & $0.831 \pm 0.013$ & 0.82 \\
\hline $\mathrm{IH}(0.5 \mu \mathrm{M})+\mathrm{GA}(132 \mu \mathrm{M})$ & $0.734 \pm 0.006$ & 0.73 & $0.680 \pm 0.045$ & 0.65 \\
\hline $\mathrm{IH}(1 \mu \mathrm{M})+\mathrm{GA}(66 \mu \mathrm{M})$ & $0.752 \pm 0.011$ & 0.75 & $0.784 \pm 0.064$ & 0.75 \\
\hline $\mathrm{IH}(1 \mu \mathrm{M})+\mathrm{GA}(132 \mu \mathrm{M})$ & $0.745 \pm 0.010$ & 0.74 & $1.029 \pm 0.100$ & 1.05 \\
\hline $\mathrm{IH}(5 \mu \mathrm{M})+\mathrm{GA}(66 \mu \mathrm{M})$ & $0.751 \pm 0.012$ & 0.74 & $0.783 \pm 0.080$ & 0.73 \\
\hline $\mathrm{IH}(5 \mu \mathrm{M})+\mathrm{GA}(132 \mu \mathrm{M})$ & $0.672 \pm 0.016$ & 0.67 & $0.987 \pm 0.197$ & 1.01 \\
\hline
\end{tabular}

Table 7

GA enhanced antitumor efficacy of $\mathrm{IH}$ in vivo.

\begin{tabular}{|c|c|c|}
\hline Groups & Tumor volume (mm3) & Inhibition rate (\%) \\
\hline Control & $3423.96 \pm 361.57$ & -- \\
\hline GA & $2684.70 \pm 790.98^{\star}$ & 21.59 \\
\hline $\mathrm{IH}$ & $2768.95 \pm 376.09 *$ & 19.13 \\
\hline $\mathrm{GA}+\mathrm{IH}$ & $2283.81 \pm 580.96^{\star \star, \#, \Delta}$ & 33.30 \\
\hline
\end{tabular}

Table 8

Protective effect of GA on IH-induced liver and nephrotoxicity 


\begin{tabular}{|c|c|c|c|c|c|}
\hline Group & $\mathrm{n}$ & ALT (U/L) & ALP (U/L) & BUN (mmol/L) & $\mathrm{Cr}(\mu \mathrm{mol} / \mathrm{L})$ \\
\hline Control & 6 & $57.15 \pm 6.23^{\star \star \star}$ & $65.0 \pm 4.2^{\star \star \star}$ & $9.5 \pm 0.6 * \star$ & $64 \pm 1.5^{\star \star}$ \\
\hline $\mathrm{GA}-30 \mu \mathrm{g} / \mathrm{kg}$ & 6 & $55.06 \pm 4.59 \# \# \#$ & $61.4 \pm 1.1^{\# \# \#}$ & $7.3 \pm 0.4^{\#}$ & $62.4 \pm 2.1^{\# \#}$ \\
\hline $\mathrm{IH}-100$ mg/kg & 6 & $56.17 \pm 5.36^{\Delta \Delta \Delta}$ & $62.8 \pm 1.9^{\Delta \Delta \Delta}$ & $7.1 \pm 0.5^{\Delta}$ & $59.8 \pm 4.4$ \\
\hline $\mathrm{GA}+\mathrm{IH}-30 \mu \mathrm{g} / \mathrm{kg}+100 \mathrm{mg} / \mathrm{kg}$ & 6 & $51.79 \pm 3.98$ & $58.0 \pm 3.8$ & $6.9 \pm 0.5$ & $56.4 \pm 3.4$ \\
\hline
\end{tabular}

\section{Figures}<smiles>O=C(O)c1cc(O)c(O)c(O)c1</smiles>

Gallic acid (GA)

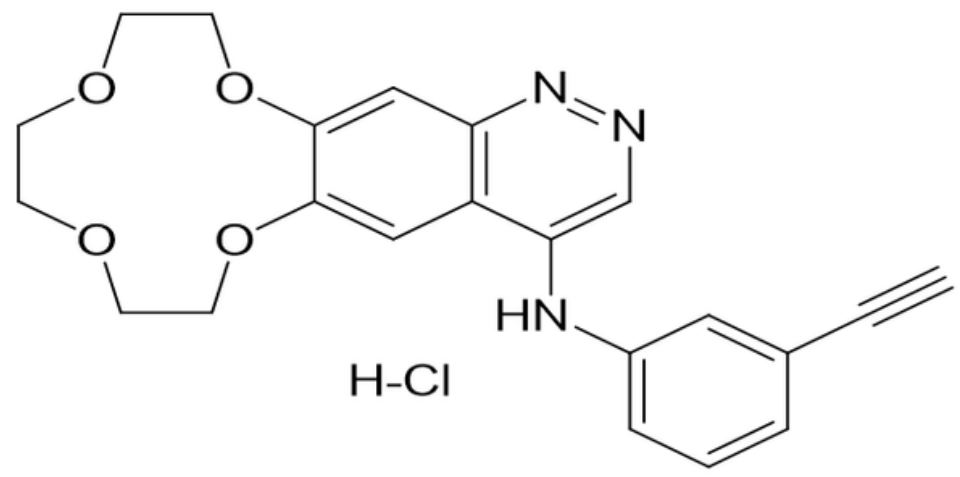

Icotinib hydrochloride $(\mathrm{IH})$

\section{Figure 1}

Chemical structure of GA (provided by SIGMA USA). Molecular formula: C7H605; Chemical structure of IH (provided by Zhejiang Beta Pharma Co. China). Molecular formula: C22H21N3O4. 

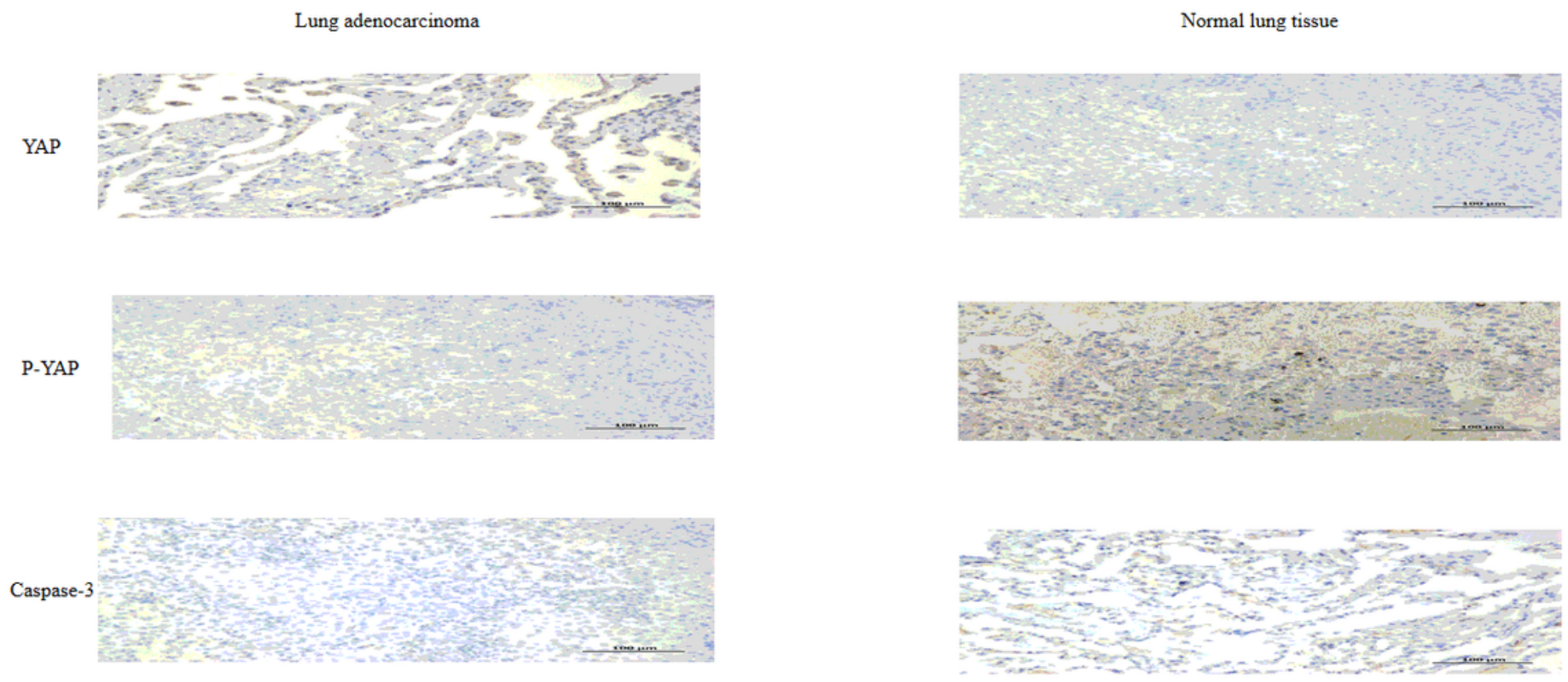

\section{Figure 2}

Representative photographs for the immunohistochemical staining of human NSCLC lung adenocarcinoma tissues (left column) and paired adjacent normal lung tissues (right column) to examine the Caspase-3, YAP and p-YAP expression $(\times 200)$. 
(A)

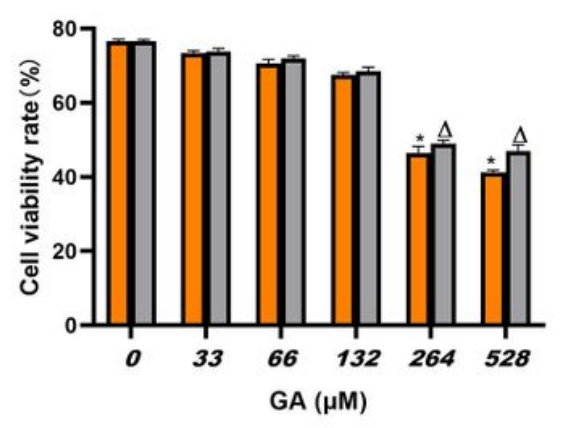

(B)

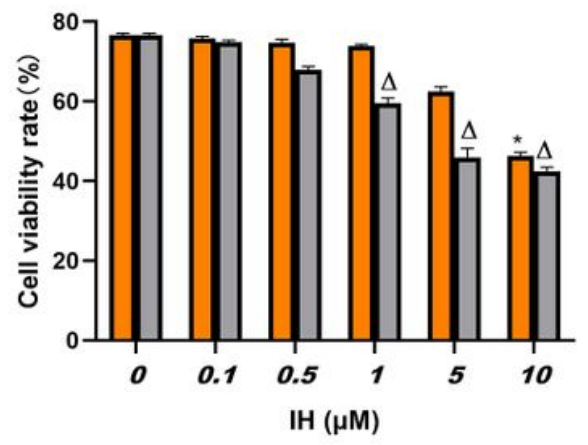

(C)

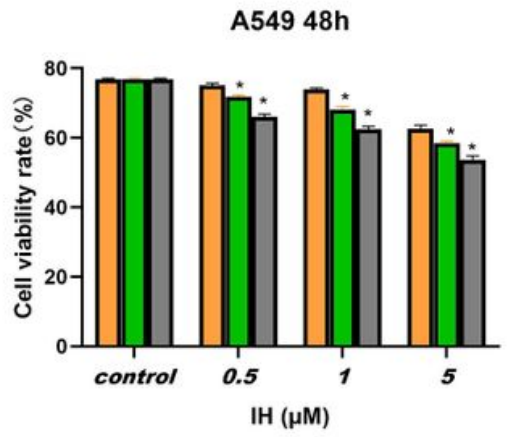

ㅁ $\mathrm{H}$

口 $\mathrm{IH}+\mathrm{GA}(66 \mu \mathrm{M})$

口 $\mathrm{IH}+\mathrm{GA}(132 \mu \mathrm{M})$
ㅁ549

ㅁ PC9

(D)

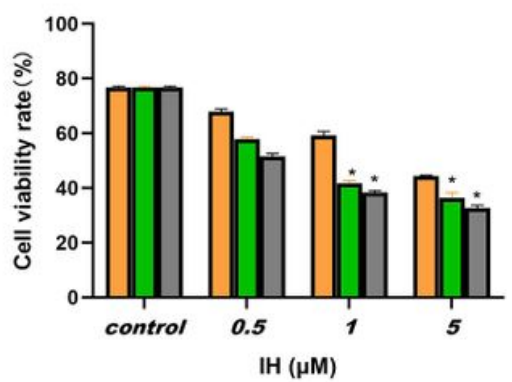

마

口 $\mathrm{IH}+\mathrm{GA}(66 \mu \mathrm{M})$

口 $\mathrm{IH}+\mathrm{GA}(132 \mu \mathrm{M})$

\section{Figure 3}

GA enhanced the drug susceptibility of IH in A549/PC9 cells. (A) A549/PC9 cells were treated with different concentrations of GA for $48 \mathrm{~h}$, the cell viability was determined by the MTT assay. (B) A549/PC9 cells were treated with different concentrations of IH for $48 \mathrm{~h}$, the cell viability was determined by the MTT assay. (C) A549 cells were treated with $\mathrm{IH}(0.5,1.0,5.0 \mu \mathrm{M})$ combined with $\mathrm{GA}(66$ or $132 \mu \mathrm{M})$, cell viability was measured by the MTT assay. (D) PC9 cells were treated with $\mathrm{IH}(0.5,1.0,5.0 \mu \mathrm{M})$ combined with scutellarin $(66$ or $132 \mu \mathrm{M})$, cell viability was measured by the MTT assay. Data are representative of three independent experiments (mean $\pm \mathrm{SEM}$ ). ${ }^{*} p<0.05 ; \triangle p<0.05$. vs the control group 
(a)
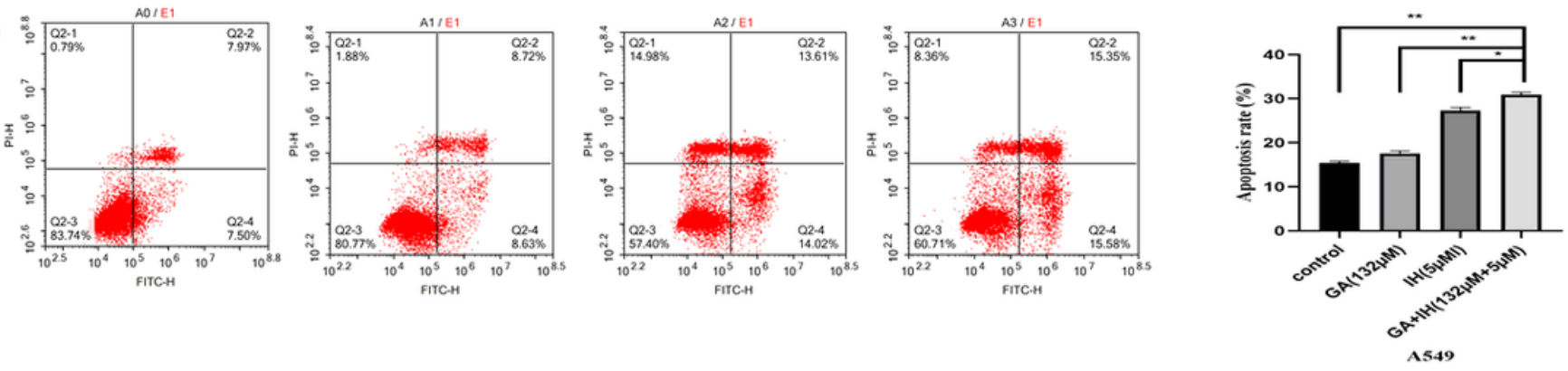

(b)
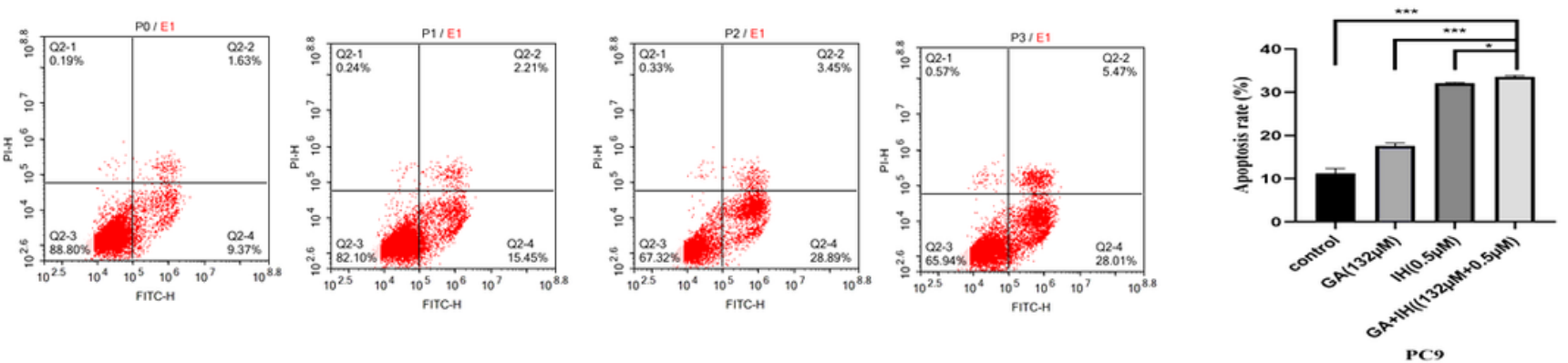

Figure 4

GA enhanced IH-induced apoptosis. Cells were exposed to IH with or without GA for $48 \mathrm{~h}$, cell apoptosis was measured by flow cytometric analysis.

(C) Western blot analysis showing caspase-3, cleaved caspase-3 and PARP expression levels in A549/DDP cells treated as indicated. Actin was used as loading control. Data are representative of three independent experiments (mean \pm SEM). 


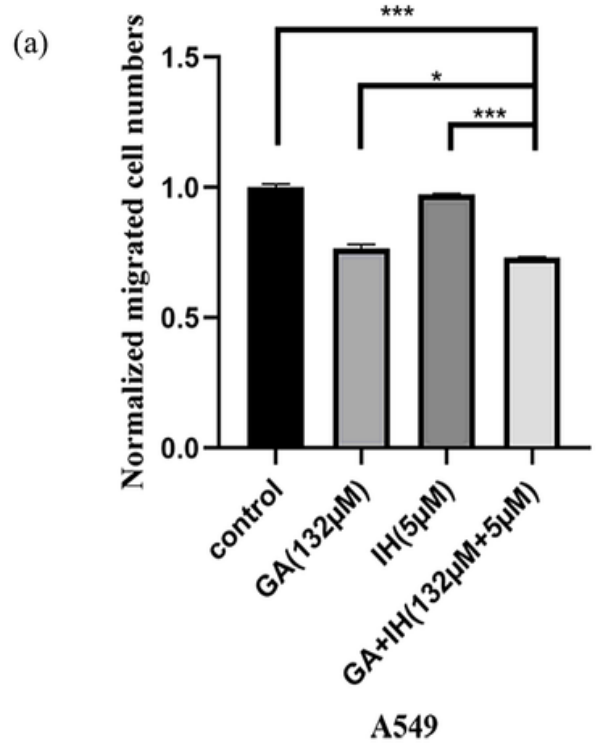

(b)

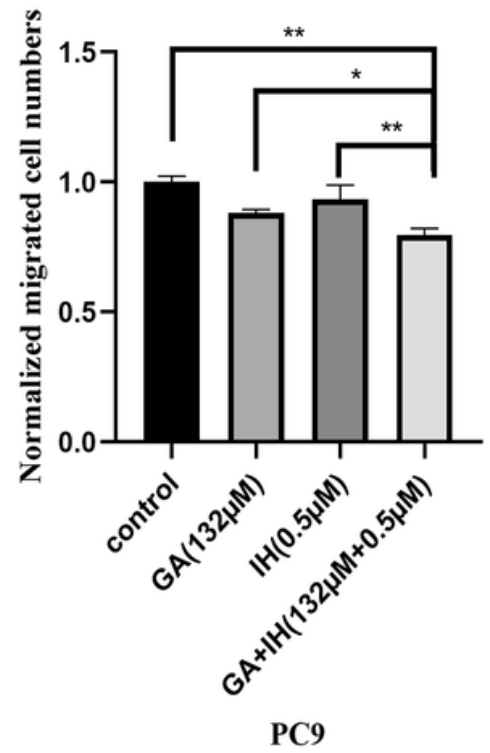

Figure 5

GA enhances IH suppressed migration. Cells were exposed to IH with or without GA for $48 \mathrm{~h}$, cell apoptosis was measured by crystal violet (a: A549; b: PC9). Data are representative of three independent experiments (mean \pm SEM). 
(a)
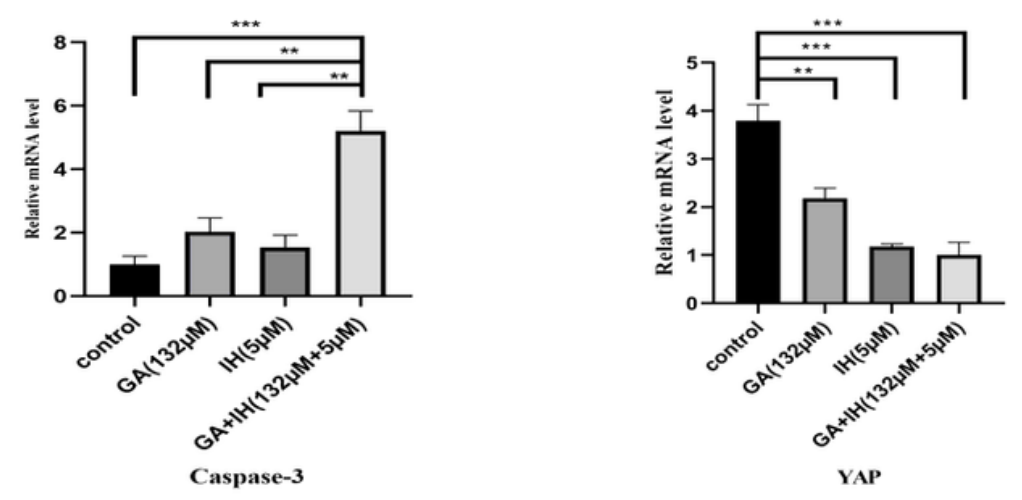

(b)
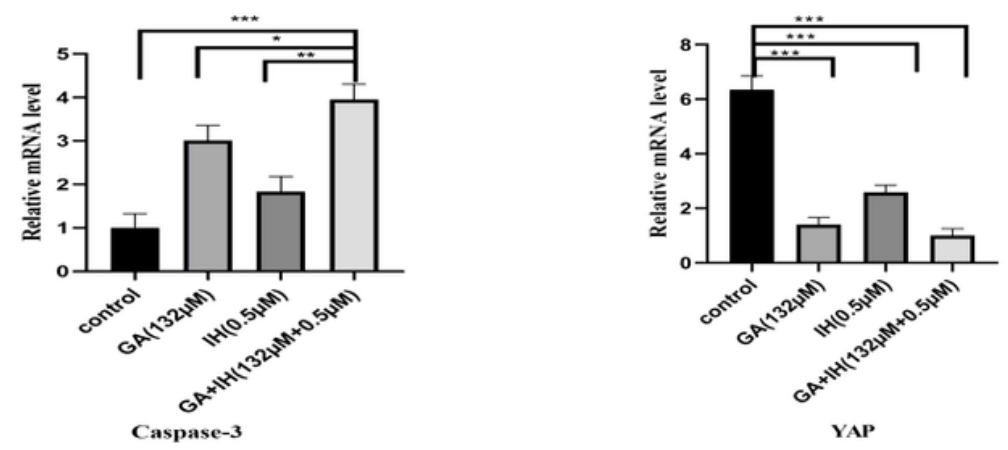

Figure 6

GA enhances IH on mRNA expression of the key gene. The relative mRNA level of two genes was quantified by the quantitative RT-PCR analysis using the $2^{-\triangle \triangle C t}$ method(a: A549; b: PC9). Data are representative of three independent experiments (mean \pm SEM). 
(a)
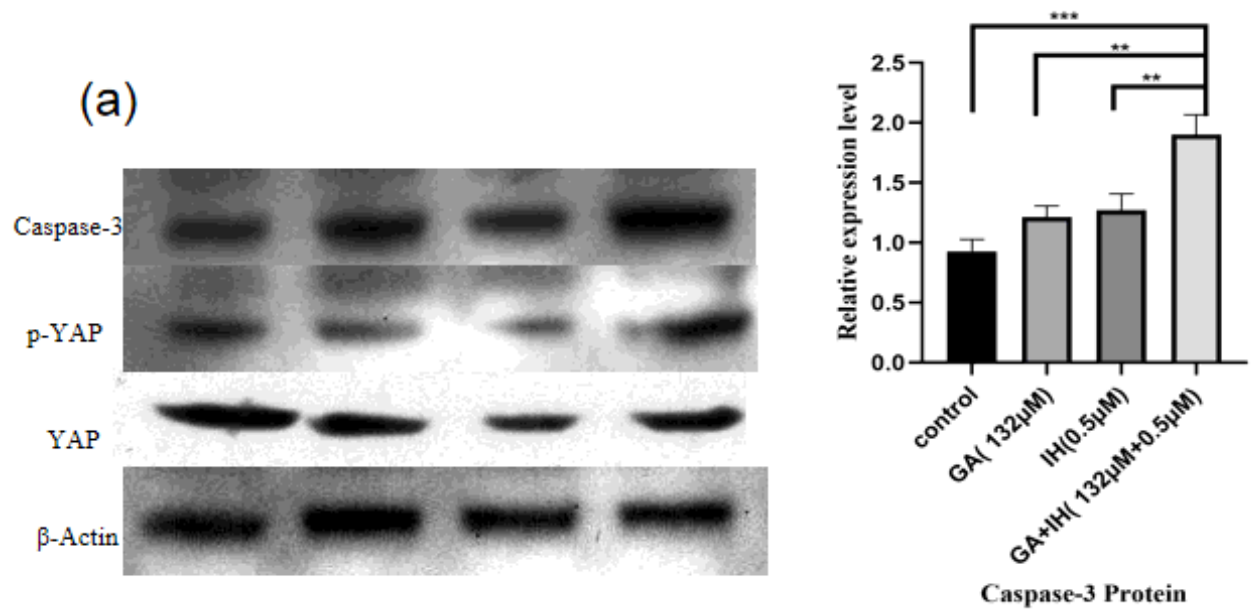

(b)

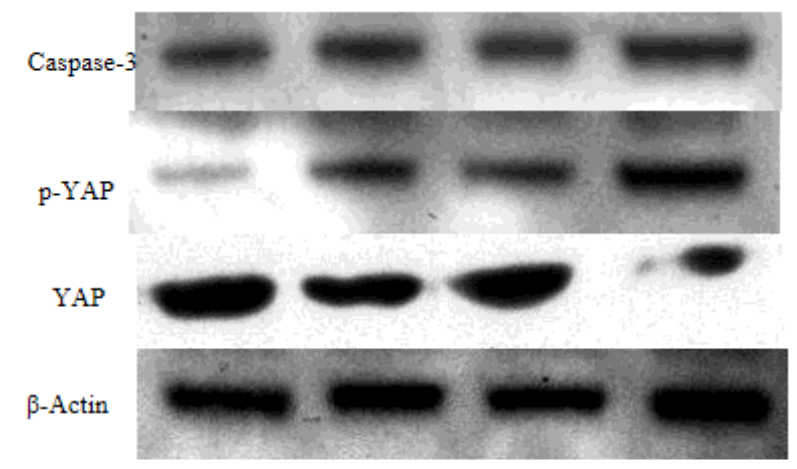

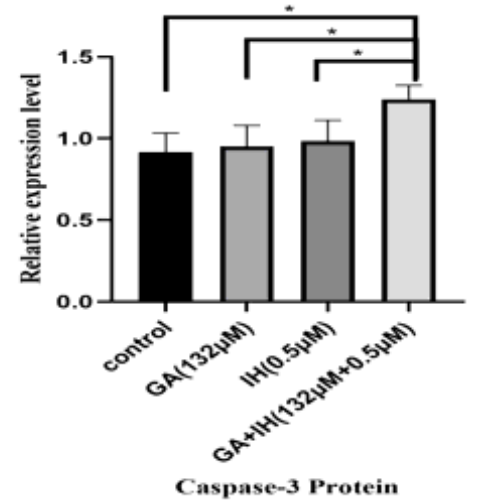
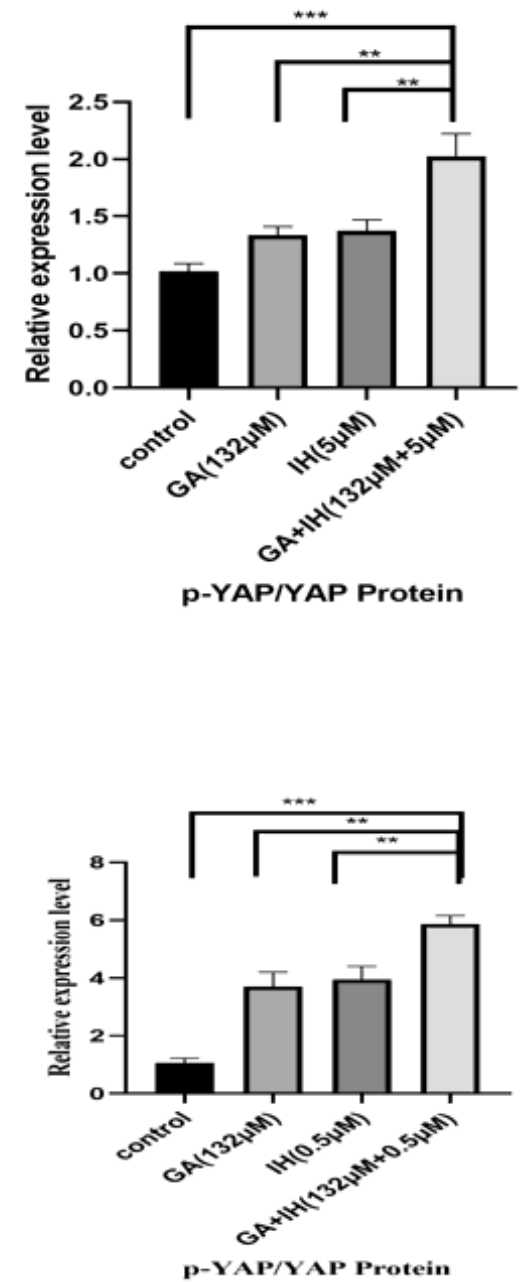

Figure 7

GA enhanced IH-induced apoptosis through the Hippo-YAP signaling pathways. Western blot analysis of caspase-3, YAP and p-YAP protein in A549/PC9 cells treated by IH, or GA, or the combination. Actin was used as loading control. Data are representative of three independent experiments (mean \pm SEM). 
(a)

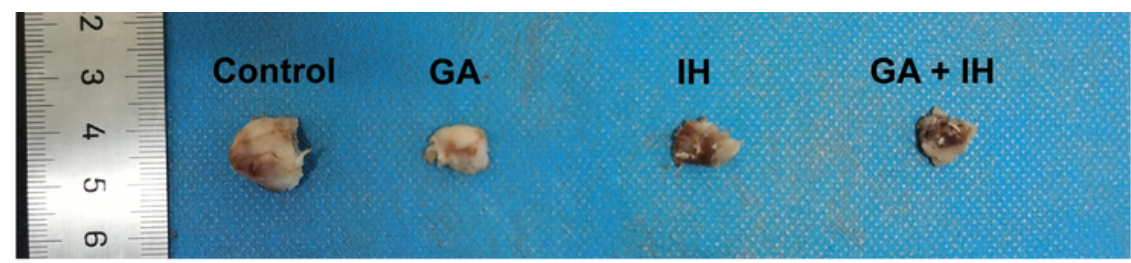

(b)
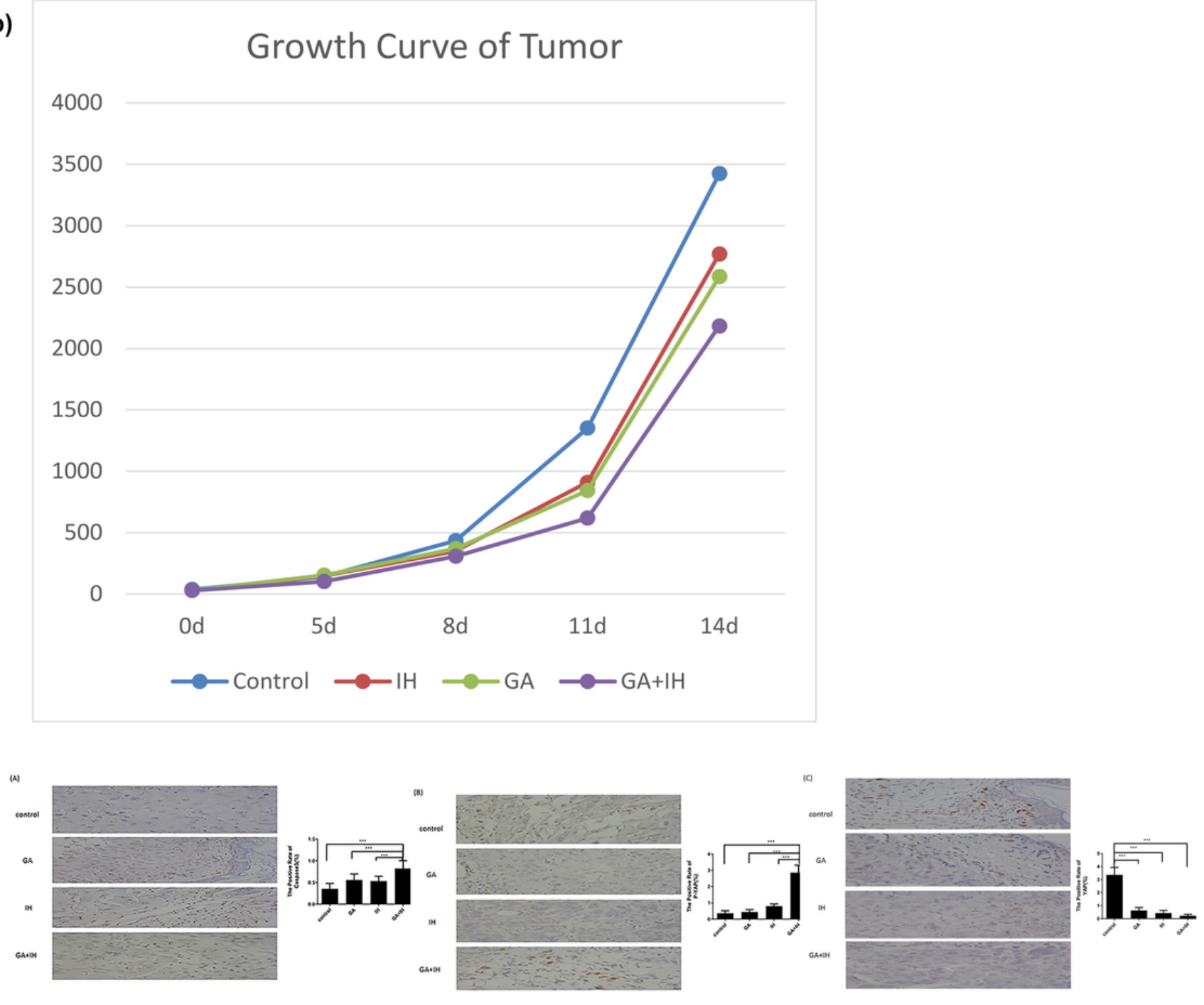

\section{Figure 8}

GA enhanced antitumor efficacy of IH in vivo. The PC9 cells were subcutaneously implanted BALB/c nude mice, and the mice were treated with IH with or without GA. (a) After treatment for 14 days, mice were humanely euthanized, and the tumor tissues were subsequently harvested. (b): The tumor dimensions were measured per 3 days using a digital caliper, tumor size in each group is shown. (c) The expression levels of caspase-3 (A), YAP (B) and p-YAP (C) in mice tumor were detected by qPCR analysis (A: caspase-3; B; p-YAP; C: YAP). Data are representative of three independent experiments (mean \pm SEM). ${ }^{* *} p<0.05$. 


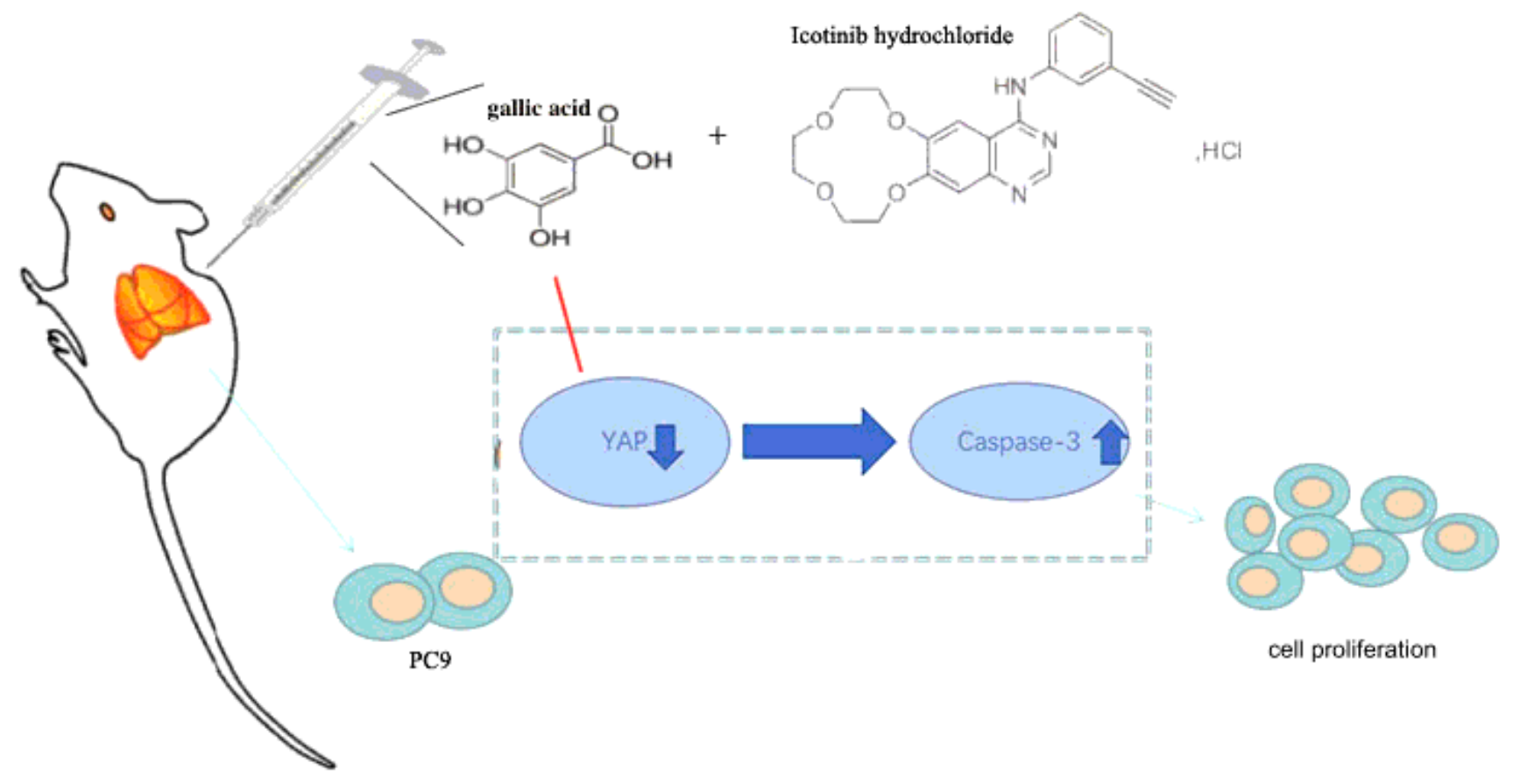

\section{Figure 9}

A mechanism map depicting the role of GA combinated with IH in the progression of NSCLC via YAP-Caspase-3 axis. Gallic acid combinated with IH disrupts the activation of YAP to enhance the expression of Caspase-3, whereby inhibiting the carcinogenic activity of YAP and repressing the development of NSCLC. 